\title{
ARTIFICIAL INTELLIGENCE IN BUSINESS AND ECONOMICS RESEARCH: TRENDS AND FUTURE
}

\author{
José Luis RUIZ-REAL (D)1, Juan URIBE-TORIL(D)1*, \\ José Antonio TORRES (12) Jaime DE PABLO(1) 1 \\ ${ }^{1}$ Faculty of Economics and Business, University of Almería, Almería, Spain \\ ${ }^{2}$ Department of Computer Science, University of Almería, Almería Spain
}

Received 29 January 2020; accepted 19 August 2020

\begin{abstract}
Artificial Intelligence is a disruptive technology developed during the 20th century, which has undergone an accelerated evolution, underpinning solutions to complex problems in the business world. Neural Networks, Machine Learning, or Deep Learning are concepts currently associated with terms such as digital marketing, decision making, industry 4.0 and business digital transformation. Interest in this technology will increase as the competitive advantages of the use of Artificial Intelligence by economic entities is realised. The aim of this research is to analyse the state-of-the-art research of Artificial Intelligence in business. To this end, a bibliometric analysis has been implement using the Web of Science and Scopus online databases. By using a fractional counting method, this paper identifies 11 clusters and the most frequent terms used in Artificial Intelligence research. The present study identifies the main trends in research on Artificial Intelligence in business and proposes future lines of inquiry.
\end{abstract}

Keywords: artificial intelligence, business, economics, bibliometrics, research trends, decisionmaking.

JEL Classification: A12, M21, O32.

\section{Introduction}

Artificial intelligence (AI) is a disruptive technological development that, together with robotics, is changing the operating model in companies in each and every one of its basic functions (Choi \& Ozkan, 2019).

AI already has a significant impact on network marketing processes and services, through the analysis of user behavior in networks and the creation of user profiles to which product and service offerings are oriented; It affects the production departments, managing maintenance in a predictive way, automating quality control and detecting anomalies in the production lines before problems occur; It influences the logistics processes, calculating efficient

\footnotetext{
${ }^{\star}$ Corresponding author. E-mail: juribe@ual.es
} 
routes, recalculating new routes based on unexpected events and maintaining contact with the client and the logistics service provider in a fluid and automatic way; It has an influence on after-sales services, analyzing the opinion of customers about products and services, to assess their level of satisfaction and possible failures or improvements that may apply to products/services (Plastino \& Purdy, 2018).

AI implies, as a disruptive technology, a change in the labor relations model and in employment itself, within the new economy (Morikawa, 2016).

The incorporation of AI into companies is increasing, as reflected in the report of MIT Sloan Management Review (2017) (in collaboration with Boston Consulting Group), which shows that $85 \%$ of CEOs consulted believe that AI offers competitive advantages to their companies, although its implementation is carried out slowly, with $20 \%$ of companies digitized with this technology.

Disruptive knowledge and technologies are elements that generate important changes in productive structures, in society and in general knowledge, making the previous structures obsolete. AI has gone from, in the twentieth century, being a branch of knowledge in the field of computer science with limited application and restricted by the capabilities of the hardware of the time, to becoming a vital element for the development of industry and services of $21^{\text {st }}$ century society.

The initial purpose of AI was to convert non-analytical human knowledge into computational data from symbolic computation processes, connectionist networks, or a mixture of both. Thus, AI was conceived as a science with double lines of analysis: correlational and theoretical. Regarding the correlational aspect, the simultaneous and/or successive occurrence of different inferential processes to which symbolic magnitudes are assigned is described. In the theoretical analysis, an explanation is sought based on a set of rules in a higher plane of knowledge that contributes to describing and predicting past and future events.

AI has been redirected towards the construction of solutions to problems with large volumes of data, which change over time, present inaccuracies and, in some cases, contradictions. The fundamental change since its development during the 1960s, 70s and 80s, and its intensive use in this century is the transition from the symbolic approach to the connectionist one. Thus, the expert systems based on rules were the spearhead of AI for the resolution of problems in fields such as: medical areas (Mutasa et al., 2020; Patel et al., 2009; van Assen et al., 2020); geology (Fedra, 1994; Lebailly et al., 1987); chemical analysis (Kozma \& Russell, 1997; Nicholson et al., 1999); data recovery using natural language (Callan et al., 1992; Shwartz et al., 1993); planning of operations for robots (Kusiak \& Chen, 1988; Rampersad, 2020), etc.

Nowadays, the systems for approaching functions using iterative techniques, and the architectures of neural networks interconnected with each other, make up most of the techniques grouped under the terms Machine Learning and Deep Learning. Its field of application has been extended, having as a common denominator the analysis of large volumes of data or complex data structures, dependent on time and unknown factors. Relevant examples of this are the works by Trafalis and Ince (2000), or Wei-Yang, Ya-Han, and Chih-Fong (2012), or Wong, Fortino, and Abbott (2020), where models based on this 
technology are presented, providing a framework compatible with the prediction of the Great Depression of 2008 (Yu et al., 2014), and a useful tool for the prediction of crisis situations in financial institutions. Financial activity has been one of the most relevant fields of application of this new AI (Jan \& Ayub, 2019; Weng et al., 2018).

However, these are not the only fields of research in AI. Companies have found a powerful ally in this technology for improving the performance of their core business, and also for supporting operational business processes. Thus, AI serves as a tool for bolstering e-commerce (Karimova, 2016); financial operations and information analysis processes for trading operations (Cavalcante et al., 2016; Ince \& Aktan, 2009; Maknickiene \& Maknickas, 2013); fraud detection processes in financial operations (West \& Bhattacharya, 2016); or textual analysis of financial information (Shravan Kumar \& Ravi, 2016; Xing et al., 2018). In addition, AI plays an important role in processes related to marketing (Chopra, 2019; Lee et al., 2020; Li et al., 2017; Stalidis et al., 2015; Wirth, 2018); customer management (Marinchak et al., 2018); product launches, after-sales services and stock management (Sheta et al., 2015; Soltani-Fesaghandis \& Pooya, 2018); or in the implementation of industry 4.0 processes (Lee \& Park, 2018; Ramakrishna et al., 2020). The introduction of specialized algorithms in these tasks generates competitive advantages, due to the speed of decision-making, the analysis of complex situations and the reduction of operating costs.

Nevertheless, AI may generate externalities that can lead to adverse situations for business. In some cases, the elimination of the human emotional component and the flexibility of thought, as well as actions not subject to strict rules, have caused problems in the financial world (overbooking of securities due to the automation of these, and use of the same rules for their activation). It can also adversely affect the manufacturing industry with relation to the lack of flexibility in the development of assembly operations in the automotive industry and in dealing with customers (rejection of purchase recommendations and actions in the framework of information analysis that compromises the legality of such actions). In any case, AI has become an integral part of the business world and its implantation as an important factor in all a company's tasks is, and will be, a reality throughout our century.

The research has been positively affected by the emergence of studies that cover both the theoretical developments of AI and its application to the business world. As previously seen, research into the practical applications has been going through different stages, from its use in different applied sciences (medicine, geology and mathematics), to developments in the world of finance and, subsequently, to all fields of economic activity. This level of research activity is reflected in the volume and quality of published works, its measurable impact on other publications and the fast rate with which new research studies appear.

The increased interest in AI in the business world is reflected in the present study, which has the following structure. First, the methodology is explained, based on a bibliometric analysis. Next, the results of the investigation are presented. Finally, conclusions, possible limitations and future lines of research are proposed. This work represents a contribution by identifying the main trends of $\mathrm{AI}$ in business, while proposing future research lines. 


\section{Methodology}

A bibliometric analysis was developed to study AI and its growing influence in business and economics publications. This methodology can be defined as the study of quantitative aspects of the production, dissemination, and use of recorded information (Tague-Sutcliffe, 1992). More informally, bibliometrics is about what people (authors) do with documents (journal articles) for what reasons, and with what effects (Furner, 2014). The collection of scientific production in Web of Science (WoS) and Scopus databases allows to measure scientific activity on specific subjects (Garfield, 1955; Bakkalbasi et al., 2006; Hirsch, 2005). These databases were chosen as the best options because of their quality and the vast number of sources of data referring to citations and summaries of peer reviewed research literature (Moed, 2005; Van Raan, 2014). In addition, VOSviewer, a freely available computer program for constructing and viewing bibliometric maps (Van Eck \& Waltman, 2010), was used to create co-citation and keyword diagrams. The clustering technique used is based on recent developments in the fields of network science and bibliometrics (Traag et al., 2011; Waltman \& Van Eck, 2012) and determines the relatedness of publications based on direct citation relations. A major advantage of the use of direct citation relations is the possibility to efficiently cluster very large numbers of publications (Van Eck \& Waltman, 2017). Recent research has shown successfully the usefulness of this methodology and provides valuable information for new research.

AI was the objective topic of this research. Thus, articles containing "Artificial Intelligence" were searched in the title, abstract, or keywords, from the first recorded document in the databases to 2018, and limited to the research areas of Business, Management, Accounting, Economics, Econometrics or Finance Knowledge. The concept of AI is broader and encompasses not only the learning and classification processes that encompasses the first concept but also procedures of great impact nowadays, such as neural deep learning networks, known as Deep Learning, and other complex data analysis models such as expert systems, genetic algorithms, Bayesian network-based models, etc.

The second step was identifying publications from reliable databases using two different scientific platforms, WoS core collection and Scopus database, frequently used in bibliometric studies (Goodman \& Deis, 2005; Guz \& Rushchitsky, 2009; Chadegani et al., 2013).

The preliminary results show 34,343 documents in WoS and 303,086 in Scopus. The references were subsequently refined, obtaining 1,187 inputs in WoS, and 7,340 in Scopus. To conclude, the search in the databases was once more filtered to select just articles. This facilitated and improved the research, ensuring the quality of the results. The final outcomes show 691 articles in WoS, and 3,112 in Scopus.

Although, according to the filter used there were only 77 articles that appeared in both databases, it was found that the articles not included in the WoS database could be found in Scopus. For that reason, the research was focused on Scopus with the exception of the Trends section, where both databases have been used in order to provide or corroborate conclusions.

The use of bibliometrics and patent analysis provide useful data (Daim et al., 2006). In the case of the Scopus database, it cross-searches patents from five patent offices: the US Office Patent and Trademark Office; the European Patent Office; Japan Patent Office; the World Intellectual Property Organization and the UK Intellectual Property Office. 


\section{Results}

\subsection{Leading countries}

The United States of America (U.S.) and The United Kingdom (UK) are on the top of the most influential countries in AI in Business research publications (Table 1), both in terms of volume of publications and citations. China, Spain and Canada complete the top five.

Regarding the h-index, the U.S. leads the ranking, followed by China and the UK. The rest of the top ten counties are in an interval close to $20 \mathrm{~h}$-index. Pertaining to the average number of citations per article, the ranking is slightly altered, led by Hong Kong (24.40). This is mainly due to six articles with a large number of citations (Sun et al., 2008; Cho, 2003; Luo et al., 2013; Wagner, 2006; Chan et al., 2000; Choy et al., 2005).

Two articles exceed 600 citations: Managerial applications of neural networks: The case of bank failure predictions, in Management Science, written in 1992 by Kar Yan Tam and Melody Yihwa Kiang. The second is Alignment between Business and IS Strategies: A Study of Prospectors, Analyzers, and Defenders, available in Information System Research. The research developed by Rajiv Sabherwal and Yolande Chan, examines the impact of alignment on perceived business performance using Miles and Snow's popular classification of business strategies.

With regards to other indices, the ranking shows three countries with a high number of patents: U.S., Hong Kong and France. This is in contrast to the results for Spain, India or Germany.

Table 1. Ranking of leading countries

\begin{tabular}{|c|c|c|c|c|c|c|}
\hline Ranking & Country & Articles & Citations & TC/A & h-index & Patent results \\
\hline 1 & U.S. & 943 & 22,230 & 23.57 & 65 & 241 \\
\hline 2 & UK & 313 & 5,389 & 17.22 & 38 & 18 \\
\hline 3 & China & 289 & 3,925 & 13.58 & 50 & 34 \\
\hline 4 & Spain & 140 & 2,115 & 15.11 & 24 & 1 \\
\hline 5 & Canada & 136 & 1,933 & 14.21 & 25 & 47 \\
\hline 6 & India & 130 & 1,535 & 11.81 & 20 & 1 \\
\hline 7 & Australia & 127 & 2,107 & 16.59 & 26 & 21 \\
\hline 8 & Germany & 124 & 1,612 & 13.00 & 22 & 4 \\
\hline 9 & France & 118 & 1,595 & 13.52 & 24 & 109 \\
\hline 10 & Hong Kong & 103 & 2,513 & 24.40 & 26 & 187 \\
\hline
\end{tabular}

Note: TC/A: Total citations/Articles.

As is the norm in research publications, English stands out well above other languages, with a $97 \%$ of articles written in that language. Since the most relevant journals on these issues publish in English, and three of the most influential countries are English speaking, the other sixteen languages are almost irrelevant in this topic. Chinese or Spanish represent less than $0.6 \%$ of the articles. 


\subsection{Publications per year}

The term AI was originally coined in the mid-1950s by the computer scientist John McCarthy. The first paper that refers to this topic in relation with business was "Applying ArtificialIntelligence to the pattern-cutters problem", by Bartin Burkhalterin, published in 1963 in Operation Research. This article, recorded on WoS, was classified in the areas of Business and Economics; Operations Research and Management Science.

Regarding the Scopus database, the first article was "Picture language interaction in artificial intelligence", by Richard Zatorski, published in 1970 in the Australian Computer Journal. The paper outlines a proposed application of the model designed by M. B. Clowes for the recovery of the structure of solid polyhedra from their representations in two-dimensional graphs to the recovery of structures underlying scenes represented in natural language. The recovery of the latter is an essential step in AI systems requiring interaction between pictures and language.

In the 1970s, only eight articles related to the subject were published. In the following decade, there was a significant increase with 274 publications. The 1990s and the beginning of the 21 st century follow similar behaviours, with small variations but along the same lines with between 536 and 559 articles. It was not until 2009 that there was a rapid increase in the number of publications, demonstrating a trend towards the creation of new publications.

\subsection{Most influential journals}

AI has a transversal nature, so articles can be found in a wide range of fields and journals. There is not a high concentration of papers in a single journal, but rather they are distributed across a range of them. Even though this research is focused on Business and Economics, there are many journals in different areas that publish articles on AI, since this topic can be related to many different fields of management and can be of use to companies in a variety of ways. In the last few years, the topic has also grown in importance in the academic field.

The most prolific journals are led by Knowledge Based Systems (486 articles), followed by Decision Support Systems (336), the International Journal of Production Research (188), and the Journal of the Operational Research Society (107). Decision Support Systems has the highest h-index (48), followed by Knowledge Based Systems (46). With regards to the number of citations, three journals can be highlighted, Decision Support Systems (9,522), Knowledge Based Systems $(8,552)$, and International Journal of Production Research $(4,358)$.

With regards to the average number of citations per article, the following journals are the most relevant: Decision Support Systems (28.34), Journal of Construction Engineering and Management (26.20), International Journal of Production Economics (24.70), and International Journal of Production Research (23.18).

Related to the impact factor of journals dealing with AI, the Journal of Cleaner Production has the highest impact factor in JCR (5.651), followed by International Journal of Production Economics (4.407), and Knowledge Based Systems (4.396). Regarding SJR, International Journal of Production Economics (2.401) has the highest impact factor, followed by Decision Support Systems (1.656), and Information and Management (1.628). These figures are important since they indicate that while some of the journals have the greatest impact factors (e.g., 
Journal of Cleaner Production and International Journal of Production Economics), they are still far from being the top in terms of the volume of publications about these topics.

Table 2 shows the top ten most cited articles. As mentioned before, Tam and Kiang (1992), published in Management Science, is the most cited paper (625 citations). This work analyses the managerial applications of neural networks in the case of bank failure predictions. Management Science is the only journal having two articles in this ranking, since the article by Das and Chen (2007) has 432 citations. The remaining journals in this ranking have published just one article in the top ten: Sabherwal and Chan (2001) in Information Systems Research; Swaminathan, Smith, and Sadeh (1998) in Decision Sciences; Rozinat and Van der Aalst (2008) in Information Systems; Huang, Chen, Hsu, Chen, and Wu (2004) in Decision Support Systems; Mylopoulos, Borgida, Jarke, and Koubarakis (1990) in ACM Transactions on Information Systems; Altman, Marco and Baretto (1994) in Journal of Banking and Finance; LeBaron, Arthur, and Palmer (1999) in Journal of Economic Dynamics and Control; and Wilson and Sharda (1994) in Decision Support Systems.

Table 2. Top ten articles - citations

\begin{tabular}{|c|c|c|c|c|}
\hline Article & $\mathrm{C}$ & Year & Authors & Journal \\
\hline $\begin{array}{l}\text { Managerial applications of neural networks: } \\
\text { The case of bank failure predictions }\end{array}$ & 625 & 1992 & $\begin{array}{l}\text { Tam, K. Y., } \\
\text { Kiang, M. Y. }\end{array}$ & $\begin{array}{l}\text { Management } \\
\text { Science }\end{array}$ \\
\hline $\begin{array}{l}\text { Alignment between Business and IS Strate- } \\
\text { gies: A Study of Prospectors, Analyzers, and } \\
\text { Defenders }\end{array}$ & 608 & 2001 & $\begin{array}{l}\text { Sabherwal, R., } \\
\text { Chan, Y. E. }\end{array}$ & $\begin{array}{l}\text { Information } \\
\text { Systems Re- } \\
\text { search }\end{array}$ \\
\hline $\begin{array}{l}\text { Modeling supply chain dynamics: A } \\
\text { multiagent approach }\end{array}$ & 557 & 1998 & $\begin{array}{l}\text { Swaminathan, J. M., } \\
\text { Smith, S. F., } \\
\text { Sadeh, N. M. }\end{array}$ & $\begin{array}{l}\text { Decision } \\
\text { Sciences }\end{array}$ \\
\hline $\begin{array}{l}\text { Conformance checking of processes based } \\
\text { on monitoring real behavior }\end{array}$ & 537 & 2008 & $\begin{array}{l}\text { Rozinat, A., Van der } \\
\text { Aalst, W. M. P. }\end{array}$ & $\begin{array}{l}\text { Information } \\
\text { Systems }\end{array}$ \\
\hline $\begin{array}{l}\text { Credit rating analysis with support vector } \\
\text { machines and neural networks: A market } \\
\text { comparative study }\end{array}$ & 505 & 2004 & $\begin{array}{l}\text { Huang, Z., } \\
\text { Chen, H., Hsu, C.-J., } \\
\text { Chen, W.-H., Wu, S. }\end{array}$ & $\begin{array}{l}\text { Decision } \\
\text { Support } \\
\text { Systems }\end{array}$ \\
\hline $\begin{array}{l}\text { Yahoo! for amazon: Sentiment extraction } \\
\text { from small talk on the Web }\end{array}$ & 432 & 2007 & $\begin{array}{l}\text { Das, S.R., } \\
\text { Chen, M. Y. }\end{array}$ & $\begin{array}{l}\text { Management } \\
\text { Science }\end{array}$ \\
\hline $\begin{array}{l}\text { Telos: Representing Knowledge About } \\
\text { Information Systems }\end{array}$ & 431 & 1990 & $\begin{array}{l}\text { Mylopoulos, J., Bor- } \\
\text { gida, A., Jarke, M., } \\
\text { Koubarakis, M. }\end{array}$ & $\begin{array}{l}\text { ACM Trans- } \\
\text { actions on } \\
\text { Information } \\
\text { Systems }\end{array}$ \\
\hline $\begin{array}{l}\text { Corporate distress diagnosis: Comparisons } \\
\text { using linear discriminant analysis and } \\
\text { neural networks (the Italian experience) }\end{array}$ & 401 & 1994 & $\begin{array}{l}\text { Altman, E. I., } \\
\text { Marco, G., } \\
\text { Varetto, F. }\end{array}$ & $\begin{array}{l}\text { Journal of } \\
\text { Banking and } \\
\text { Finance }\end{array}$ \\
\hline $\begin{array}{l}\text { Time series properties of an artificial stock } \\
\text { market }\end{array}$ & 378 & 1999 & $\begin{array}{l}\text { LeBaron, B., } \\
\text { Arthur, W. B., } \\
\text { Palmer, R. }\end{array}$ & $\begin{array}{l}\text { Journal of } \\
\text { Economic } \\
\text { Dynamics and } \\
\text { Control }\end{array}$ \\
\hline $\begin{array}{l}\text { Bankruptcy prediction using neural } \\
\text { networks }\end{array}$ & 363 & 1994 & $\begin{array}{l}\text { Wilson, R.L., } \\
\text { Sharda, R. }\end{array}$ & $\begin{array}{l}\text { Decision Sup- } \\
\text { port Systems }\end{array}$ \\
\hline
\end{tabular}

Note: C: Total number of citations. 


\subsection{Most relevant authors, affiliations and cited references}

Table 3 shows the most prolific of the 190 authors listed in Scopus. The three authors who had the greatest number of articles published were Professors Hamido Fugita, King Lun Tommy Choy and George To Sum Ho, with nine articles each.

Professor Fugita, from the Iwate Prefectural University, Faculty of Software and Information Science in Iwate, Japan, is a featured author with 277 documents on the Scopus database and 2,315 citations. This author has written about AI from a business and economics perspective in nine articles, published between 2016 and 2018.

The second most prolific author is Professor Choy, from the Department of Industrial and Systems of the Hong Kong Polytechnic University. The first article published by Choy about AI and Business was in 2005 and describes a knowledge-based supplier selection and evaluation system, which is a case-based reasoning decision support system for outsourcing operations at Honeywell Consumer Products. Professor Ho, from the same university is the third most prolific author. These two authors have collaborated on five of the nine articles.

The most cited article of the most prolific authors is Demirkan and Delen (2013), which contributes new knowledge in service science by linking the information technology strategy perspectives to the database and design science perspectives for a broader audience.

Table 3. Most prolific authors

\begin{tabular}{|l|c|c|c|c|c|c|c|}
\hline \multicolumn{1}{|c|}{ Author } & A & C & C/A & h-index & MC & 1 st & Last \\
\hline Fujita, H. & 9 & 196 & 21.78 & 7 & 69 & 2015 & 2018 \\
\hline Choy, K.L.T. & 9 & 171 & 19.00 & 5 & 110 & 2004 & 2018 \\
\hline Ho, G.T.S. & 9 & 80 & 8.89 & 4 & 32 & 2005 & 2018 \\
\hline Pendharkar, P.C. & 8 & 66 & 8.25 & 5 & 23 & 1999 & 2015 \\
\hline Delen, D. & 7 & 331 & 47.29 & 5 & 246 & 2011 & 2018 \\
\hline Lau, H.C.W. & 7 & 198 & 28.29 & 6 & 110 & 2002 & 2012 \\
\hline Lu, J. & 6 & 300 & 50.00 & 5 & 115 & 2010 & 2018 \\
\hline Zhang, G. & 6 & 300 & 50.00 & 5 & 115 & 2010 & 2018 \\
\hline Whinston, A.B. & 6 & 251 & 41.83 & 5 & 197 & 1985 & 2001 \\
\hline Turban, E. & 6 & 247 & 41.17 & 5 & 153 & 1986 & 1995 \\
\hline Herrera-Viedma, E. & 6 & 217 & 36.17 & 5 & 69 & 2016 & 2017 \\
\hline Kimbrough, S.O. & 6 & 126 & 21.00 & 5 & 57 & 1993 & 2014 \\
\hline O’Leary, D.E. & 6 & 86 & 14.33 & 4 & 25 & 1987 & 2015 \\
\hline
\end{tabular}

Note: C/A: Citations/Articles; MC: Most cited article; $1^{\text {st. }}$ Year of first publication; Last: Year of the last publication.

\subsection{Contribution of Institutions and funding sponsors}

Various public and private organizations have helped to promote research and disseminate knowledge through the publication of articles. Table 4 shows the main universities promoting research on AI in the field of Business and Economics. Five of the universities that lead this ranking are in the United States (U.S.), four are in China and only two universities are 
located in Europe. The main university in this field is Hong Kong Polytechnic University, with 59 articles, and an h-index of 19. The outstanding leadership of the Hong Kong Polytechnic University (PolyU) in terms of the number of publications is mainly due to its commitment to research in AI in various fields. The university has its own research centre and it has been developing numerous activities to encourage research and teaching about the potential of AI. In 2018, these initiatives included the Artificial Intelligence in Fashion and Textile (AIFT) Conference 2018; an academic conference to explain how AI improves the shopping experience; a workshop on AI; a Certificate Programme for Students and a seminar on AI in the Career Path of Accounting and Finance. Finally, the Institute of Textiles and Clothing of PolyU collaborates with Alibaba Group to promote the use of AI in the fashion industry by integrating fashion knowledge and machine learning formulation. These types of initiatives and commitment to research have allowed PolyU to lead the number of publications on AI in Business and Economics.

Nevertheless, the main universities related to the search for AI related patents are the University of Arizona (25), Carnegie Mellon University (21), and City University of Hong Kong (13). The first two universities with the greatest number of patents on AI also have the highest average of citations per article: the University of Arizona (56.18) and Carnegie Mellon University (54.14). The University of Arizona has developed the Artificial Intelligence Laboratory (AI Lab) which is well known for contributions in health informatics, security informatics, business intelligence and knowledge management. Over the last 30 years AI Lab has received more than 40 million dollars in research funding from the National Science Foundation (NSF), the National Institute of Health (NIH), the National Library of Medicine (NLM), the Department of Justice (DOJ), the National Institute of Justice (NIJ), Defense Advanced Research Projects Agency (DARPA), the Central Intelligence Agency (CIA), the National Center for Supercomputing Applications (NCSA), and other agencies and corporations (University of Arizona Website). Carnegie Mellon University (CMU) is a private non-profit research university based in Pennsylvania and it is one of the most outstanding research centres in the U.S. in the area of computer science and robotics, having a great reputation in AI and business. Some of the first AI software programs were created at CMU, including Logic Theorist, General Problem Solver, and Soar. CMU School of Computer Science also initiated a new undergraduate degree in AI in 2018. City University of Hong Kong (CityU) has also developed different programs on AI, such as Engineering Applications of Artificial Intelligence or Logistics and Artificial Intelligence. Universities with a higher number of patents have programs that relate scientific and academic research with its practical application in the field of business management in many different sectors, many of them promoted jointly with companies and some other institutions.

There are also several funding agencies sponsoring research on AI in Business and Economics. The top ten is led in number by European entities: the European Commission (EC), the European Regional Development Fund (FEDER), the Engineering and Physical Sciences Research Council (EPSRC) from the UK, and the Federación Española de Enfermedades Raras (FEDER) from Spain. Nevertheless, China is the most prolific country in terms of volume of articles sponsored. Specifically, the National Natural Science Foundation of China (NSFC) has supported the publication of 144 articles to date, far exceeding the number of articles published by the other entities. Other Asian organisations such as Hong Kong Polytechnic 
University (PolyU) and National Science Council of Taiwan (NSC) are also relevant in this area. The National Science Foundation (NSF) in the U.S., the Natural Sciences and Engineering Research Council of Canada (NSERC), and the Australian Research Council (ARC) complete the top ten of this ranking.

Table 4. Institutions promoting research

\begin{tabular}{|l|c|c|c|c|c|}
\hline \multicolumn{1}{|c|}{ Institution } & A & C & C/A & h-i & PR \\
\hline Hong Kong Polytechnic University & 59 & 1,338 & 22.68 & 19 & 4 \\
\hline Purdue University & 29 & 495 & 17.07 & 13 & 0 \\
\hline Virginia Polytechnic Institute and State University & 27 & 531 & 19.67 & 12 & 0 \\
\hline City University of Hong Kong & 24 & 531 & 22.13 & 12 & 13 \\
\hline University of Arizona & 22 & 1,236 & 56.18 & 15 & 25 \\
\hline Carnegie Mellon University & 22 & 1,191 & 54.14 & 13 & 21 \\
\hline University of Texas at Austin & 21 & 863 & 41.10 & 13 & 1 \\
\hline Erasmus University Rotterdam & 21 & 550 & 26.19 & 10 & 0 \\
\hline National University of Singapore & 19 & 408 & 21.47 & 10 & 7 \\
\hline Universidad de Granada & 19 & 474 & 24.95 & 11 & 1 \\
\hline Shanghai Jiao Tong University & 19 & 128 & 6.74 & 7 & 1 \\
\hline
\end{tabular}

Note: A: Articles; C: Citations; C/A: Citations/Article; h-i: Hirsch index; PR: Patent results.

\subsection{Trends}

A map based on the co-occurrence of the authors' keywords was developed for this research by using a fractional counting method (Figure 1) using VOSviewer software. Note that the clusters have been determined by a statistical technique and not by an a priori delineation of topics. Naturally, it is to be hoped that the clustering technique leads to recognizable topics, but it has to be explicitly investigated whether this is actually the case (Waaijer et al., 2011). VOSviewer uses a natural language processing technique when extracting terms from the text corpus file. A term is defined as a sequence of nouns and adjectives ending with a noun (Van Eck \& Waltman, 2015).

The minimum of occurrences of a keyword was established as five for the 6,063 keywords found. This map is useful for understanding trends and shows connections between the most frequent terms.

Eleven groups were identified, with the most relevant topics presented below:

- Cluster 1 (red) (25 items): Decision support system, simulation, decision making, clustering, information systems, project management, decision analysis, probability, economics, decision making, Analytic Hierarchy Process (AHP), multi-criteria analysis.

- Cluster 2 (green) (22 items): Classification, feature selection, artificial neural networks, group decision making, supervised learning, credit risk, credit scoring, decision tree, bankruptcy prediction, expert system, prediction, random forest, logistic regression, discriminant analysis, data mining. 
- Cluster 3 (dark blue) (22 items): Ant colony optimization, genetic algorithm, scheduling, meta-heuristics, differential evolution, negotiation, multi-agent system, computational intelligence, evolutionary algorithm.

- Cluster 4 (mustard) (20 items): Supply chain management, transportation, logistics, operations management, modelling, evolutionary algorithms, reinforcement learning, inventory management, lean manufacturing, vehicle routing.

- Cluster 5 (purple) (17 items): Artificial intelligence, risk management, genetic algorithms, automation, semantic web, information technology, knowledge, robots, ontologies, information retrieval, Decision Support System (DSS).

- Cluster 6 (light blue) (16 items): Machine learning, text mining, social media, Twitter, natural language processing, business intelligence, predictive analytics, e-commerce, recommender systems, life cycle assessment, opinion mining, sentiment analysis.

- Cluster 7 (orange) (16 items): Big data, case-based reasoning, robotics, intelligent agents, condition monitoring, clinical decision support system, privacy, ethics, quality, Internet of the things, cloud computing.

- Cluster 8 (brown) (11 items): Forecasting, active learning, artificial neural network, algorithms, Adaptive Neuro-Based Fuzzy Inference System (ANFIS), support vector machine, fuzzy logic.

- Cluster 9 (pink) (11 items): Knowledge management, deep learning, electronic commerce, marketing, Internet, trust, technology, tourism, pattern recognition.

- Cluster 10 (salmon) (11 items): Sustainability, planning, complexity, case study, strategy, product development, risk assessment.

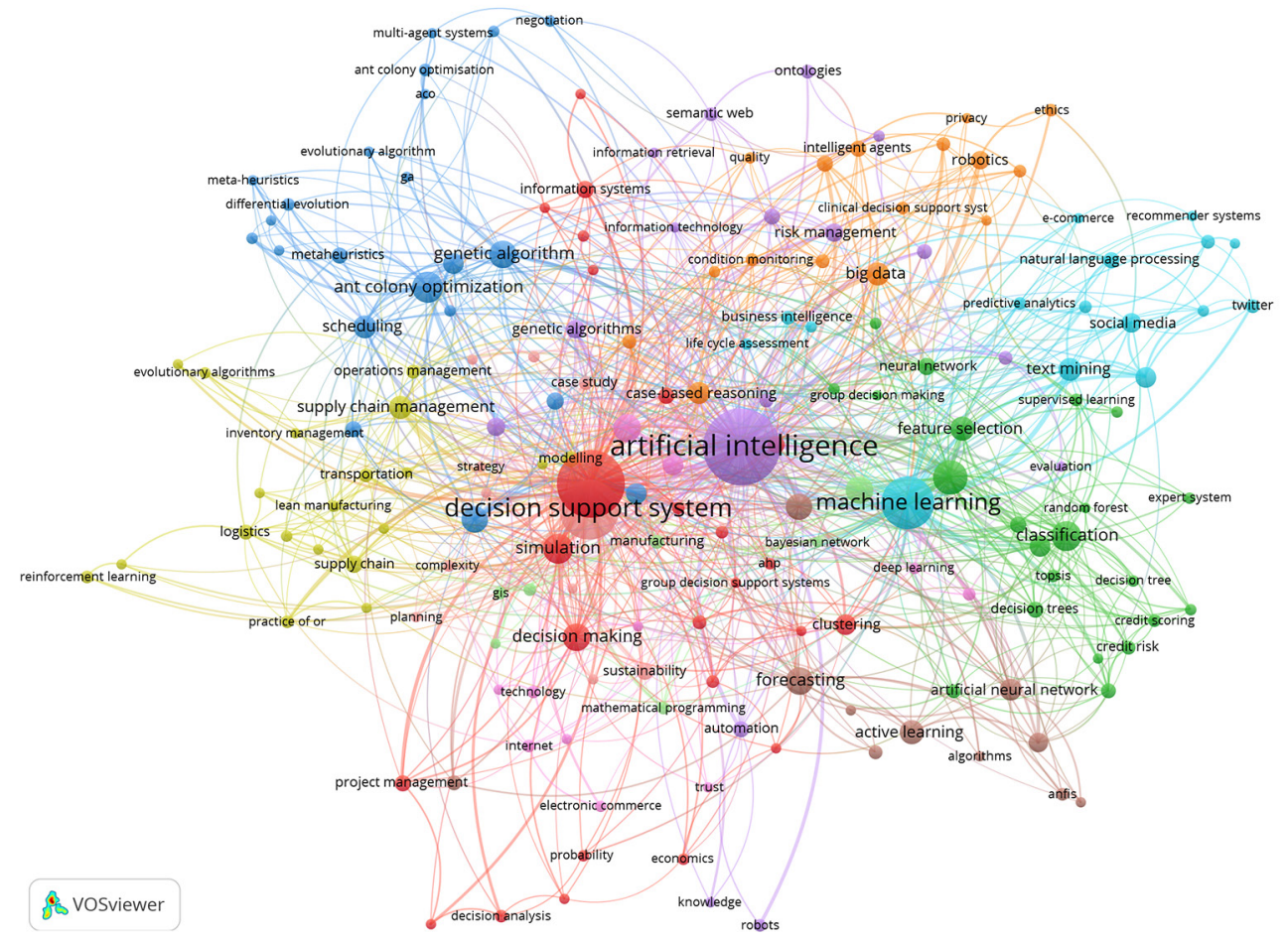

Figure 1. WOS co-occurrence author's keywords map 

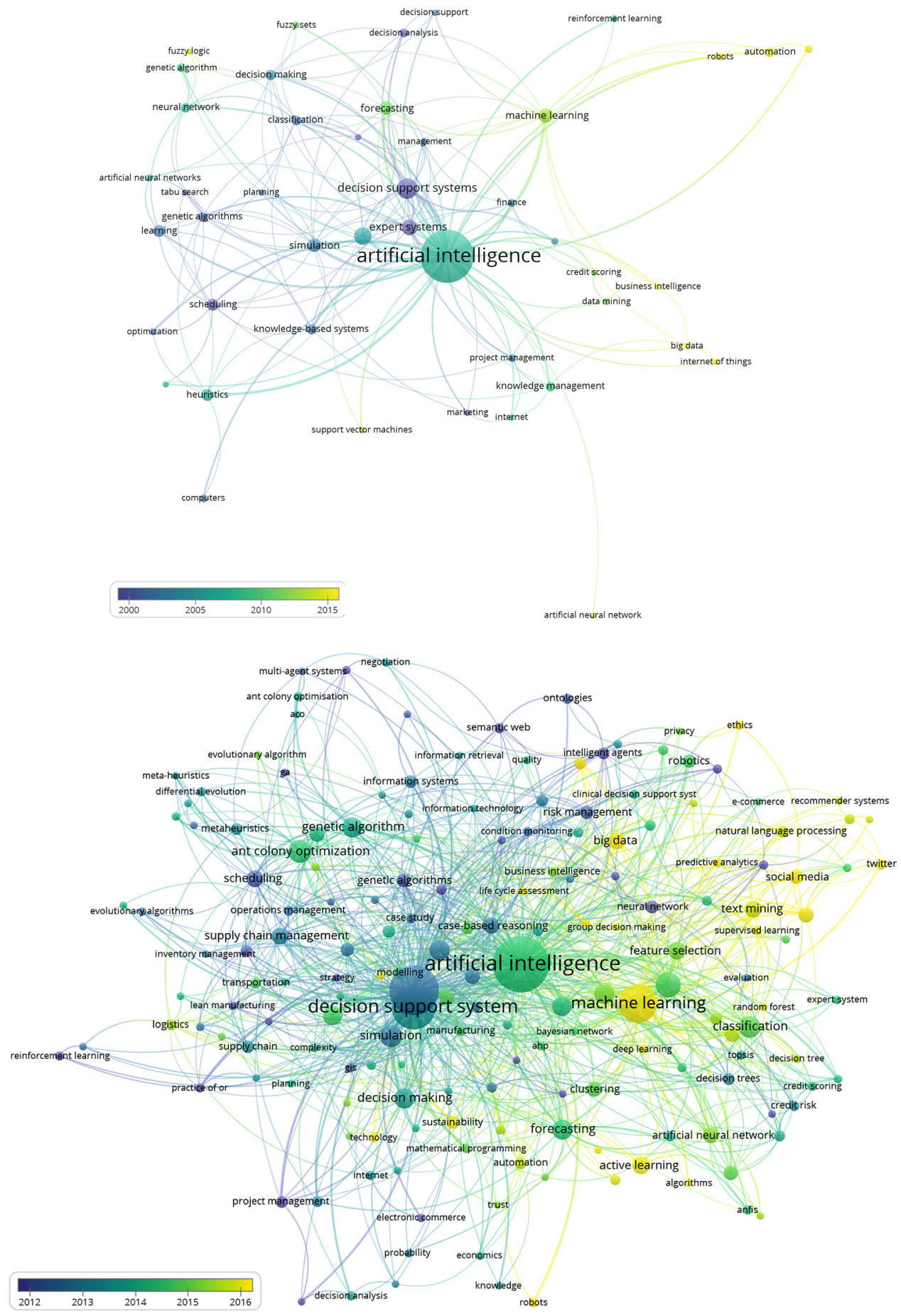

Figure 2. Co-occurrence evolution map (WoS and Scopus) 
- Cluster 11 (light green) (7 items): Mathematical programming, manufacturing, Bayesian network, Geographic Information System (GIS), knowledge-based system.

For identifying the development of author's frequent terms researching AI in Business and Economics, two trend maps were made in accordance with the data available on the WOS and Scopus (Figure 2) databases, by using a full counting method and based on bibliographic data on co-occurrence on the authors keywords. The most recent keywords are marked in yellow in order to better identify the most important trends.

Several emergent topics are identified and grouped by themes. Thus, research and trends are focused on: machine learning, active learning and supervised learning; big data, intelligence agents and business intelligence; social media and Twitter; the Internet of Things, technology and robots (automation); ethics and sustainability; predictive analytics, group decision making, life cycle assessment, algorithms, modelling and fuzzy logics.

\section{Discussion}

The research verifies the growth of scientific interest in the application of AI in business. The evolution pointed out by Scopus and the interrelationships between the works identified through VOSviewer confirm the growing scientific interest in the synergy between AI and business. The term AI was originally coined in the mid-1950s and the first paper that refers AI in relation to business was in 1963. In the 1970s, only eight articles related to the subject were published. The evolution of the number of papers related to business and AI is parallel to the total articles published on AI. An accelerated growth in the number of publications can be observed from 2008, changing a trend of stagnation that lasted for decades. The incorporation of Machine Learning and, later, Deep Learning, as tools for solving complex problems in the world of data, has sparked interest in these topics.

The research of AI as a strategic pillar of business competitiveness, and as a differentiating element of the new economy in the countries with greater economic strength, is outlined by the results of Table 1 which shows the countries with the greatest number of patents and the greatest concentration of quality researchers who carry out these works (based on the h-index and the numbers of citations of their articles). The United States of America (U.S.) and The United Kingdom (UK) are the most influential countries in this topic. Regarding the h-index, the U.S. leads the ranking, followed by China and the UK. Five of the main universities promoting research on AI in the field of Business and Economics are from the U.S., although Hong Kong Polytechnic University is the main university in this field, focusing research in AI on different fields. The interest of the U.S., China (Hong Kong) and France can be observed through the practical application of the results obtained, leading the number of patents.

Research on AI may be found in a wide range of fields and journals, due to its transversal nature, so articles are distributed across a range of them. Even research focused on Business and Economics may be found in several journals since AI can be related to different fields of management. Anyway, the most prolific journals are Knowledge Based Systems, Decision Support Systems and International Journal of Production Research. Decision Support Systems has also the highest h-index. Related to the number of citations, Decision Support Systems 
is the main journal. The Journal of Cleaner Production has the highest impact factor in JCR, followed by International Journal of Production Economics. It is worth noting that while some journals have the greatest impact factors, they are not the most important journals in terms of volume of articles on these topics. Finally, some European entities and funding agencies led the ranking of sponsored research on AI in Business and Economics.

The three authors with the higher number of articles are Professors Fugita (Iwate Prefectural University, Japan) Choy and Ho (Hong Kong Polytechnic University).

Emergent topics have been identified and grouped by subjects; thus, eleven clusters were identified. Trends are focused on: machine learning, active learning and supervised learning; big data, intelligence agents and business intelligence; social media and Twitter; the Internet of Things, technology and robots (automation); ethics and sustainability; predictive analytics, group decision making, life cycle assessment, algorithms, modelling and fuzzy logics.

Over the years, AI has copied the human quality of continuous learning, complex data analysis and reasoned prediction of future states of a phenomenon based on current knowledge. AI inherits from the computer its processing capacity, supported by the continuous increase and technological improvement of CPUs, GPUs and, in general, all processing systems. New concepts in AI, such as Deep Learning or Machine Learning are moving, in most applications, the symbolic AI of expert systems based on rules. The research of the most referenced authors already indicates what is of interest to the scientific community, in terms of applications of these technologies.

\section{Conclusions}

From a technical point of view, and in accordance with the results of the research, it is reasonable to think of a future in which scientific works focus on some of the following aspects:

Emergence of specific hardware for the implementation of AI solutions. The current supply of this hardware is concentrated in a few companies, such as Google, which has developed TensorFlow technology acceleration units (Tensor Processing Units or TPUs), or NVIDIA, incorporating circuitry (Tensor Cores) to accelerate the training processes of neural networks (base of Deep Learning). In the coming years it will be possible to observe the emergence of specialized hardware in the computation of AI applications (Nvidia DGX-2 is just the beginning) to increase the potential of this technology.

Standardization of the internal structures of neural networks that make up the Deep Learning algorithms, to be used and implemented more broadly and efficiently (similar to what happened with the architectures of neural networks in the last century).

Development of realistic simulations of behaviours and attitudes considered to be human to improve the perception of AI applications in processes of interaction with clients (Customer Service Systems in natural language, modulated with emotional input). Some early examples of this would be the Google duplex service for telephone support, or the Magic Leap development of augmented reality with interactive AI, presented at the Unite Berlin Conference in 2018.

In terms of economic activity, $\mathrm{AI}$ is a disruptive process, both in the activity of companies and in the secondary activity of their different departments. Its deployment in all fields of business activity is unstoppable. AI has become essential in aspects as diverse as: financial 
products trading, risk analysis of insurance companies, the development of biotechnological products, transport fleets control, telecommunications management, strategies of marketing and customer service, etc.

Strong competition makes it necessary for companies to innovate and constantly reinvent themselves in order to maintain their economic activity and profitability. The concept of digital transformation of a company is aligned with other technologies in AI. Thus, scientific papers and publications will also have to address the following issues:

Incorporation of AI-based services in more and more company departments. A company immersed in digital transformation is a business focused 24 hours a day on customers' needs, with the ability to analyse the data that comes from its constant interaction with customers who are also immersed in the digital world. AI is the perfect ally for this new form of business-client relationship.

Improvement of relations with the administration and with other companies in the exchange of information contextualized in accounting, fiscal data management, operations management with suppliers, financial services management and the automation tasks that involve a significant volume of time and cost and do not generate real value to the company.

Incorporation of AI in decision making at the highest level. Companies such as Deep Knowledge Ventures or Aging Analytics already incorporate AI services in their Boards of Directors, which make investment decisions. In some cases, these services have the status of a member of the Board of Directors.

The process of social digitalization and the transformation that Industry 4.0 is generating in the expectations and consumption habits of clients, together with the huge amount of data that needs to be analysed, classified and structured, leads us to think that many of the highlevel technical tasks that are currently carried out by specialized personnel will be left to AI.

Data analysis, customer relationship management and the production processes of certain products and services (especially in finance, insurance and information services) will be highly conditioned by the application of an autonomous AI with the capacity to make decisions. This has implications both in the framework of labour relations and in the legal framework. In this sense, future research could also focus on:

The incorporation of new jobs related to AI. Data engineers have now been joined by data processing specialists, application development engineers using Deep Learning, AI behaviour analysts, etc.

Conciliation between the current technical workforce and the new work services. AI is a disruptive technology, as was the steam engine for the Industrial Revolution. Companies should be aware of the value of the human workforce in solving unexpected problems and their ad hoc solutions, situations in which automation of any kind can falter.

One of the most worrying aspects is how the civil rights of people can be preserved when AI systems manage certain activities that were traditionally developed by public officials. The following are issues open to investigation and discussion: the preservation of the right to privacy, the responsible management of personal data, freedom of expression and the right to anonymity that can be seriously violated when AI applies analysis to the data. AI feeds on particular information, which must be chosen very carefully to avoid including information that would be contrary to civil rights in the algorithms. 
The research related to the synergy analysed in this article will increase as AI adapts to these and other fields of economic activity, and scientific studies researching it will increase its relevance in the total of works published in the field of engineering and business.

This research is not exempt from certain limitations, some of them directly derived from the characteristics of the bibliometric analysis, mainly focused on quantitative issues. Some authors may publish only a few articles but be quite influential in their area of knowledge or in a specific field. This is the reason why, in addition to using WOS and Scopus for a bibliometric analysis, this work also measures qualitative features and standardized metrics, such as the number of citations. Other limitation concerns about the very nature of the bibliometric methodology. For instance, citations take time to accumulate and some papers need years after publication for being reliable. Future research could be also employed other databases or tools (e.g., Google Scholar or meta-analysis) and, in addition, could be interesting to combine bibliometric analysis with systematic literature review. In contrast, given the rapid expansion of $\mathrm{AI}$ in many fields of business, future research could also focus on different industrial sectors (e.g., retailing, transport, tourism, etc.), or different aspects of management (e.g., marketing, finance, administration, human resources), since this work deals with the general field of business.

\section{References}

Altman, E. I., Marco, G., \& Varetto, F. (1994). Corporate distress diagnosis: Comparisons using linear discriminant analysis and neural networks (the Italian experience). Journal of Banking and Finance, 18(3), 505-529. https://doi.org/10.1016/0378-4266(94)90007-8

Bakkalbasi, N., Bauer, K., Glover, J., \& Wang, L. (2006). Three options for citation tracking: Google Scholar, Scopus and Web of Science. BMC Biomedical Digital Libraries, 3(7), 1-8. https://doi.org/10.1186/1742-5581-3-7

Burkhalter, B. (1963). Applying artificial-intelligence to pattern-cutters problem. Operations Research, $11,39$.

Callan, J. P., Croft, W. B., \& Harding, S. M. (1992). The INQUERY retrieval system. In Database and expert systems applications (pp. 78-83). Springer Vienna. https://doi.org/10.1007/978-3-7091-7557-6_14

Cavalcante, R., Brasileiro, R. C., Souza, V. L. F., Nobrega, J. P., \& Oliveira, A. L. I. (2016). Computational intelligence and financial markets: A survey and future directions. Expert Systems with Applications, 55, 194-211. https://doi.org/10.1016/j.eswa.2016.02.006

Chadegani, A. A., Salehi, H., Yunus, M., Farhadi, H., Fooladi, M., Farhadi, M., \& Ale Ebrahim, N. (2013). A comparison between two main academic literature collections: Web of Science and Scopus databases. Asian Social Science, 9(5), 18-26. https://doi.org/10.5539/ass.v9n5p18

Chan, F. T. S., Jiang, B., \& Tang N. K. H. (2000). Development of intelligent decision support tools to aid the design of flexible manufacturing systems. International Journal of Production Economics, 65(1), 73-84. https://doi.org/10.1016/S0925-5273(99)00091-2

Cho, V. (2003). A comparison of three different approaches to tourist arrival forecasting. Tourism Management, 24(3), 323-330. https://doi.org/10.1016/S0261-5177(02)00068-7

Choi, J. J., \& Ozkan, B. (2019). Innovation and disruption: Industry practices and conceptual bases. In J. J. Choi \& B. Ozkan (Eds.), Disruptive innovation in business and finance in the digital world (Vol. 20, pp. 3-13). Emerald Publishing Limited.

https://doi.org/10.1108/S1569-376720190000020003 
Chopra, K. (2019). Indian shopper motivation to use artificial intelligence: Generating Vroom's expectancy theory of motivation using grounded theory approach. International Journal of Retail \& Distribution Management, 47(3), 331-347. https://doi.org/10.1108/IJRDM-11-2018-0251

Choy, K. L., Lee, W. B., Lau, H. C. W., \& Choy, L. C. (2005). A knowledge-based supplier intelligence retrieval system for outsource manufacturing. Knowledge-Based Systems, 18(1), 1-17. https://doi.org/10.1016/j.knosys.2004.05.003

Daim, T. U., Rueda, G., Martin, H., \& Gerdsri, P. (2006). Forecasting emerging technologies: Use of bibliometrics and patent analysis. Technological Forecasting and Social Change, 73(8), 981-1012. https://doi.org/10.1016/j.techfore.2006.04.004

Das, S. R., \& Chen, M. Y. (2007). Yahoo! for amazon: Sentiment extraction from small talk on the Web. Management Science, 53(9), 1375-1388. https://doi.org/10.1287/mnsc.1070.0704

Dermirkan, H., \& Delen, D. (2013). Leveraging the capabilities of service-oriented decision support systems: Putting analytics and big data in cloud. Decision Support Systems 55(1), 412-421. https://doi.org/10.1016/j.dss.2012.05.048

Fedra, K. (1994). Models, GIS, and expert systems: integrated water resources models. In K. Kovar \& H. P. Nachtnebel (Eds.), Applications of geographic information systems in hydrology and water resources management (pp. 297-308). IAHS.

Furner, J. (2014). The ethics of evaluative bibliometrics. In B. Cronin, \& C. Sugimoto (Eds.), Beyond bibliometrics: Harnessing multidimensional indicators of scholarly impact (pp. 85-107). MIT Press.

Garfield, E. (1955). Citation index for science. A new dimension in documentation through association of ideas. Science, 122(3159), 108-111. https://doi.org/10.1126/science.122.3159.108

Goodman, D., \& Deis, L. (2005). Web of Science (2004 version) and Scopus. The Charleston Advisor, $6(3), 5-21$.

Guz, A. N., \& Rushchitsky, J. J. (2009). Scopus: A system for the evaluation of scientific journals. International Applied Mechanics, 45(4), 351-362. https://doi.org/10.1007/s10778-009-0189-4

Hirsch, J. E. (2005). An index to quantify an individual's scientific research output. Proceedings of the National academy of Sciences, 102(46), 16569-16572. https://doi.org/10.1073/pnas.0507655102

Huang, Z., Chen, H., Hsu, C.-J., Chen, W.-H., \& Wu, S. (2004). Credit rating analysis with support vector machines and neural networks: A market comparative study. Decision Support Systems, 37(4), 543-558. https://doi.org/10.1016/S0167-9236(03)00086-1

Ince, H., \& Aktan, B. (2009). A comparison of data mining techniques for credit scoring in banking: A managerial perspective. Journal of Business Economics and Management, 10(3), 233-240. https://doi.org/10.3846/1611-1699.2009.10.233-240

Jan, M. N., \& Ayub, U. (2019). Do the Fama and French five-factor model forecast well using ANN? Journal of Business Economics and Management, 20(1), 168-191. https://doi.org/10.3846/jbem.2019.8250

Karimova, F. (2016). A survey of e-commerce recommender systems. European Scientific Journal, 12(34), 75-89. https://doi.org/10.19044/esj.2016.v12n34p75

Kozma, R. B., \& Russell, J. (1997). Multimedia and understanding: Expert and novice responses to different representations of chemical phenomena. Journal of Research in Science Teaching, 34(9), 949-968. https://doi.org/10.1002/(SICI)1098-2736(199711)34:9<949::AID-TEA7>3.0.CO;2-U

Kusiak, A., \& Chen, M. (1988). Expert systems for planning and scheduling manufacturing systems. European Journal of Operational Research, 34(2), 113-130. https://doi.org/10.1016/0377-2217(88)90346-3

Lebailly, L., Martin-Clouaire, R., \& Prade, A. (1987). Use of fuzzy logic in a rule-based system in petrolium geology. In Approximate reasoning on Intelligent Systems, Decision and Control (pp. 125-144). https://doi.org/10.1016/B978-0-08-034335-8.50015-5 
LeBaron, B., Arthur, W. B., \& Palmer, R. (1999). Time series properties of an artificial stock market. Journal of Economic Dynamics and Control, 23(9-10), 1487-1516. https://doi.org/10.1016/S0165-1889(98)00081-5

Lee, L. W., Dabirian, A., McCarthy, I. P., \& Kietzmann, J. (2020). Making sense of text: Artificial intelligence-enabled content analysis. European Journal of Marketing, 54(3), 615-644. https://doi.org/10.1108/EJM-02-2019-0219

Lee, Y. K., \& Park, D. W. (2018). Design of internet of things business model with deep learning artificial intelligence. International Journal of Grid and Distributed Computing, 11(7), 11-22. https://doi.org/10.14257/ijgdc.2018.11.7.02

Li, B., Hou, B., Yu, W., Lu, X., \& Yang, C. (2017). Applications of artificial intelligence in intelligent manufacturing: A review. Frontiers of Information Technology \& Electronic Engineering, 18(1), 8696. https://doi.org/10.1631/FITEE.1601885

Luo, H., Du, B., Huang, G. Q., Chen, H., \& Li, X. (2013). Hybrid flow shop scheduling considering machine electricity consumption cost. International Journal of Production Economics, 146(2), 423-439. https://doi.org/10.1016/j.ijpe.2013.01.028

Maknickiene, N., \& Maknickas, A. (2013). Financial market prediction system with Evolino neural network and Delphi method. Journal of Business Economics and Management, 14(2), 403-413. https://doi.org/10.3846/16111699.2012.729532

Marinchak, C. L. M., Forrest, E., \& Hoanca, B. (2018). The impact of artificial intelligence and virtual personal assistants on marketing. In D. B. A. M. Khosrow-Pour (Ed.), Encyclopedia of information science and technology (4th ed., pp. 5748-5756). IGI Global. https://doi.org/10.4018/978-1-5225-2255-3.ch499

McCarthy, J. (1960). Programs with common sense (pp. 300-307). RLE and MIT Computation Center.

Miles, R. E., \& Snow, C. C. (1986). Organizations: New concepts for new forms. California Management Review, 28(3), 62-73. https://doi.org/10.2307/41165202

MIT Sloan Management Review. (2017). Reshaping business with artificial intelligence. Closing the gap between ambition and action. https://sloanreview.mit.edu/projects/reshaping-business-with-artificial-intelligence/

Moed, H. F. (2005). Citation analysis in research evaluation. Springer, Dordrecht.

Morikawa, M. (2016). The effects of artificial intelligence and robotics on business and employment: Evidence from a survey on Japanese firms. Research Institute of Economy, Trade and Industry (RIETI).

Mutasa, S., Sun, S., \& Ha, R. (2020). Understanding artificial intelligence based radiology studies: What is overfitting? Clinical Imaging, 65, 96-99. https://doi.org/10.1016/j.clinimag.2020.04.025

Mylopoulos, J., Borgida, A., Jarke, M., \& Koubarakis, M. (1990). Telos: Representing knowledge about information systems. ACM Transactions on Information Systems, 8(4), 325-362. https://doi.org/10.1145/102675.102676

Nicholson, J. K., Lindon, J. C., \& Holmes, E. (1999). "Metabonomics": Understanding the metabolic responses of living systems to pathophysiological stimuli via multivariate statistical analysis of biological NMR spectroscopic data. Xenobiotica, 29(11), 1181-1189.

https://doi.org/10.1080/004982599238047

Patel, V. L., Shortliffe, E. H., Stefanelli, M., Szolovits, P., Berthold, M. R., Bellazzi, R., \& Abu-Hanna, A. (2009). The coming of age of artificial intelligence in medicine. Artificial Intelligence in Medicine, 46(1), 5-17. https://doi.org/10.1016/j.artmed.2008.07.017

Plastino, E., \& Purdy, M. (2018). Game changing value from artificial intelligence: Eight strategies. Strategy \& Leadership, 46(1), 16-22. https://doi.org/10.1108/SL-11-2017-0106

Ramakrishna, S., Ngowi, A., De Jager, H., \& Awuzie, B. O. (2020). Emerging industrial revolution: Symbiosis of Industry 4.0 and circular economy: The role of universities. Science Technology and Society, 25(3), 505-525. https://doi.org/10.1177/0971721820912918 
Rampersad, G. (2020). Robot will take your job: Innovation for an era of artificial intelligence. Journal of Business Research, 116, 68-74. https://doi.org/10.1016/j.jbusres.2020.05.019

Rozinat, A., \& Van der Aalst, W. M. P. (2008). Conformance checking of processes based on monitoring real behaviour. Information Systems, 33(1), 64-95. https://doi.org/10.1016/j.is.2007.07.001

Sabherwal, R., \& Chan, Y. E. (2001). Alignment between business and IS strategies: A study of prospectors, analyzers, and defenders. Information System Research, 12(1), 11-33. https://doi.org/10.1287/isre.12.1.11.9714

Sheta, F. A., Ahmed, S. E. M., \& Faris, H. (2015). A comparison between regression, artificial neural networks and support vector machines for predicting stock market index. International Journal of Advanced Research in Artificial Intelligence, 4(7). https://doi.org/10.14569/IJARAI.2015.040710

Shravan Kumar, B., \& Ravi, V. (2016). A survey of the applications of text mining in financial domain. Knowledge-Based Systems, 114, 128-147. https://doi.org/10.1016/j.knosys.2016.10.003

Shwartz, I. S., Richard, E., Gregory, S., Haven, N., \& Donald, P. (1993). Database retrieval system having a natural language interface. Google Patents. https:/patents.google.com/patent/US5197005A/en

Soltani-Fesaghandis, G., \& Pooya, A. (2018). Design of an artificial intelligence system for predicting success of new product development and selecting proper market-product strategy in the food industry. International Food and Agribusiness Management Review, 21(7), 847-864. https://doi.org/10.22434/IFAMR2017.0033

Stalidis, G., Karapistolis, D., \& Vafeiadis, A. (2015). Marketing decision support using artificial intelligence and knowledge modeling: Application to tourist destination management. Procedia - Social and Behavioral Sciences, 175, 106-113. https://doi.org/10.1016/j.sbspro.2015.01.1180

Sun, Z.-L., Choi, T.-M., Au, K.-F., \& Yu, Y. (2008). Sales forecasting using extreme learning machine with applications in fashion retailing. Decision Support Systems, 46(1), 411-419. https://doi.org/10.1016/j.dss.2008.07.009

Swaminathan, J. M., Smith, S. F., \& Sadeh, N. M. (1998). Modeling supply chain dynamics: A multiagent approach. Decision Sciences, 29(3), 607-631. https://doi.org/10.1111/j.1540-5915.1998.tb01356.x

Tague-Sutcliffe, J. (1992). An introduction to informetrics. Information Processing \& Management, 28(1), 1-3. https://doi.org/10.1016/0306-4573(92)90087-G

Tam, K. Y., \& Kiang, M. Y. (1992). Managerial applications of neural networks: The case of bank failure prediction. Management Science, 38(7), 926-947. https://doi.org/10.1287/mnsc.38.7.926

Traag, V. A., Van Dooren, P., \& Nesterov, Y. (2011). Narrow scope for resolution-limit-free community detection. Physical Review E, 84(1), 016114. https://doi.org/10.1103/PhysRevE.84.016114

Trafalis, T., \& Ince, H. (2000). Support vector machine for regression and applications to financial forecasting. In Proceedings of the IEEE-INNS-ENNS International Joint Conference on Neural Networks. IJCNN 2000. Neural Computing: New Challenges and Perspectives for the New Millennium (vol. 6, pp. 348-353). https://doi.org/10.1109/IJCNN.2000.859420

Van Assen, M., Lee, S. J., \& De Cecco, C. N. (2020). Artificial intelligence from A to Z: From neural network to legal framework. European Journal of Radiology, 129, 109083. https://doi.org/10.1016/j.ejrad.2020.109083

Van Eck, N. J., \& Waltman, L. (2010). Software survey: VOSviewer, a computer program for bibliometric mapping. Scientometrics, 84, 523-538. https://doi.org/10.1007/s11192-009-0146-3

Van Eck, N. J., \& Waltman, L. (2015), “VOSviewer manual”, Manual for VOSviewer Version 1.6.1. Universiteit Leiden.

Van Eck, N. J., \& Waltman, L. (2017). Citation-based clustering of publications using CitNetExplorer and VOSviewer. Scientometrics, 111(2), 1053-1070. https://doi.org/10.1007/s11192-017-2300-7

Van Raan, A. F. (2014). Advances in bibliometric analysis: Research performance assessment and science mapping. In W. Blockmans, L. Engwall, \& D. Weaire, Bibliometrics. Use and abuse in the review 
of research performance (pp. 17-28). Portland Press Ltd. https://portlandpress.com/DocumentLibrary/Umbrella/Wenner\%20Gren/Vol\%2087/WG_87_chapter\%203.pdf

Waaijer, C. J., Van Bochove, C. A., \& van Eck, N. J. (2011). On the map: Nature and science editorials. Scientometrics, 86(1), 99-112. https://doi.org/10.1007/s11192-010-0205-9

Wagner, C. (2006). Breaking the knowledge acquisition bottleneck through conversational knowledge management. Information Resources Management Journal, 19(1), 70-83. https://doi.org/10.4018/irmj.2006010104

Waltman, L., \& Van Eck, N. J. (2012). A new methodology for constructing a publication-level classification system of science. Journal of the American Society for Information Science and Technology, 63(12), 2378-2392. https://doi.org/10.1002/asi.22748

Wei-Yang, L., Ya-Han, H., \& Chih-Fong, T. (2012). Machine learning in financial crisis prediction: A survey. IEEE Transactions on Systems, Man, and Cybernetics, Part C (Applications and Reviews), 42(4), 421-436. https://doi.org/10.1109/TSMCC.2011.2170420

Weng, B., Martínez, W., Tsai, Y. T., Li, C., Lu, L., Barth, J. R., \& Megahed, F. M. (2018). Macroeconomic indicators alone can predict the monthly closing price of major US indices: Insights from artificial intelligence, time-series analysis and hybrid models. Applied Soft Computing, 71, 685-697. https://doi.org/10.1016/j.asoc.2018.07.024

West, J., \& Bhattacharya, M. (2016). Intelligent financial fraud detection. Computers \& Security, 57, 47-66. https://doi.org/10.1016/j.cose.2015.09.005

Wilson, R. L., \& Sharda, R. (1994). Bankruptcy prediction using neural networks. Decision Support Systems, 11(5), 545-557. https://doi.org/10.1016/0167-9236(94)90024-8

Wirth, N. (2018). Hello marketing, what can artificial intelligence help you with? International Journal of Market Research, 60(5), 435-438. https://doi.org/10.1177/1470785318776841

Wong, K. K. L., Fortino, G., \& Abbott, D. (2020). Deep learning-based cardiovascular image diagnosis: A promising challenge. Future Generation Computer Systems, 110, 802-811. https://doi.org/10.1016/j.future.2019.09.047

Xing, F. Z., Cambria, E., \& Welsch, R. E. (2018). Natural language based financial forecasting: A survey. Artificial Intelligence Review, 50(1), 49-73. https://doi.org/10.1007/s10462-017-9588-9

Yu, Q., Miche, Y., Séverin, E., \& Lendasse, A. (2014). Bankruptcy prediction using Extreme Learning Machine and financial expertise. Neurocomputing, 128, 296-302.

https://doi.org/10.1016/j.neucom.2013.01.063

Zatorski, R. J. (1970). Picture-language interaction in the artificial intelligence. Australian Computer Journal, 2(4), 173-179. 